\title{
PANAMÁ: PARAÍSO IMPERFECTO
}

\section{Panama: Imperfect Paradise}

\section{CLARA INÉS LUNA}

Centro de Iniciativas Democráticas de Panamá (CIDEM)

\section{SALVADOR SÁNCHEZ}

Centro de Iniciativas Democráticas de Panamá (CIDEM)

\section{RESUMEN}

El 2008 estuvo marcado por la continuación de un proceso electoral interno en los partidos políticos, que se prolongó largamente y que se libró sin cuartel, presagiando el tono de los comicios generales de mayo de 2009. También ha sido un año especial por la inusual inflación que movilizó a importantes sectores para exigir mejoras salariales, más subsidios e, incluso, control de precios. No obstante, el país siguió creciendo a tasas muy por encima del promedio latinoamericano y registró una importante caída en la pobreza y la indigencia. Desde afuera Panamá puede parecer un paraíso, pero su evidente imperfección corre el riesgo de profundizarse.

Palabras clave: Panamá, democracia, crecimiento económico, elecciones, gobernabilidad.

\begin{abstract}
2008 was marked by the continuation of an internal election process within political parties, which lasted long and was fought without quarter, presaging the tone of the general elections of May 2009. It has also been a special year because an unusual inflation that mobilized union members, medical associations, carriers, educators and retirees, demanding better incomes, more benefits and even price controls, to the central government. However, the country continued to grow at rates well above the average for Latin America and recorded a significant decline in poverty and indigence. Panama from the outside may seem like a paradise, but its obvious imperfection risk further.
\end{abstract}

Key words: Panama, democracy, economic growth, elections, gobernability. 
Panamá ha sido descrito como el resultado de la confluencia entre la cultura caribeña, la geografía centroamericana y la historia suramericana. De esa confluencia aflora cíclicamente una riqueza material nada discreta, que ha parecido un paraíso a más de un visitante ocasional. Describir a Panamá como un paraíso sirve ciertamente a varios propósitos: sirve para la promoción turística y para la autosatisfacción provinciana, y también sirve cuando la pretensión del hablante es descalificar al país y su particular desempeño en la economía global, agregándole el apellido de fiscal. Sin embargo, la realidad panameña dista mucho de poder agotarse en el retrato paradisíaco de los afiches promocionales y, definitivamente, Panamá no es un paraíso fiscal, y mucho menos es un paraíso para cerca del cuarenta por ciento de los panameños que viven en condiciones de pobreza.

Durante 2008 la actividad política estuvo marcada por la continuación de los procesos intrapartidarios para designar candidatos para las elecciones generales de mayo de 2009. Para este periodo preelectoral y electoral, habrá más de 2 millones de votantes habilitados. El 53, 23\% de los electores, según el padrón electoral serán menores de 40 años. Resalta que la incesante actividad política de 2008 se hace simultánea de la moderación del ritmo de crecimiento económico, y de la confirmación de signos de desencanto en la opinión pública, independientemente de los indicadores macroeconómicos. 2008 se ha mostrado así como un año especialmente propicio para tomar nota de las imperfecciones de ésta comunidad política, y perfilar su derrotero.

\section{TEMAS SALIENTES DE LA REALIDAD NACIONAL Y SU IMPACTO POLÍTICO}

\section{Coyuntura económica}

Panamá siguió liderando el crecimiento económico de la región, ubicándose en cuarto lugar, tras Uruguay (11.5\%), Saint Kitts y Nevis (9.7\%) y Perú (9.4\%). En 2008 el PIB creció $9,2 \%$ con respecto al año inmediatamente anterior, alcanzando un valor de B/. 18.558, 1 millones (a precios de comprador de 1996).

Aunque este crecimiento es muy importante, marca una inflexión en la tendencia de incremento de la actividad económica que por varios periodos había mantenido el país (ver Gráfico 1).

Otros agregados macroeconómicos continuaron su tendencia favorable, aunque en magnitudes menores a las presentadas en años anteriores. Se redujo el desempleo que se situó en 6, 3\% de la fuerza laboral (ver Gráfico 2). Sin embargo, un informe de la OIT reveló que la tasa de desempleo en los jóvenes es del 18,9\%. La tasa de informalidad ha gravitado en los últimos años alrededor del $45 \%$ de los ocupados, lo que representó en 2008471 mil personas con puestos de trabajo de baja productividad, sin acceso a la seguridad social y con mayor exposición al riesgo. Los sectores con mayor crecimiento de mano de obra fueron la industria manufacturera, el comercio, hoteles y restaurantes y el sector servicios. En relación al empleo en el sector público, en 2008 el Estado panameño contó con 169.070 funcionarios, de los cuales sólo el 11,5\% eran eventuales. El 68,9\% 
Gráfico 1: Crecimiento Económico de Panamá (2003-2008)

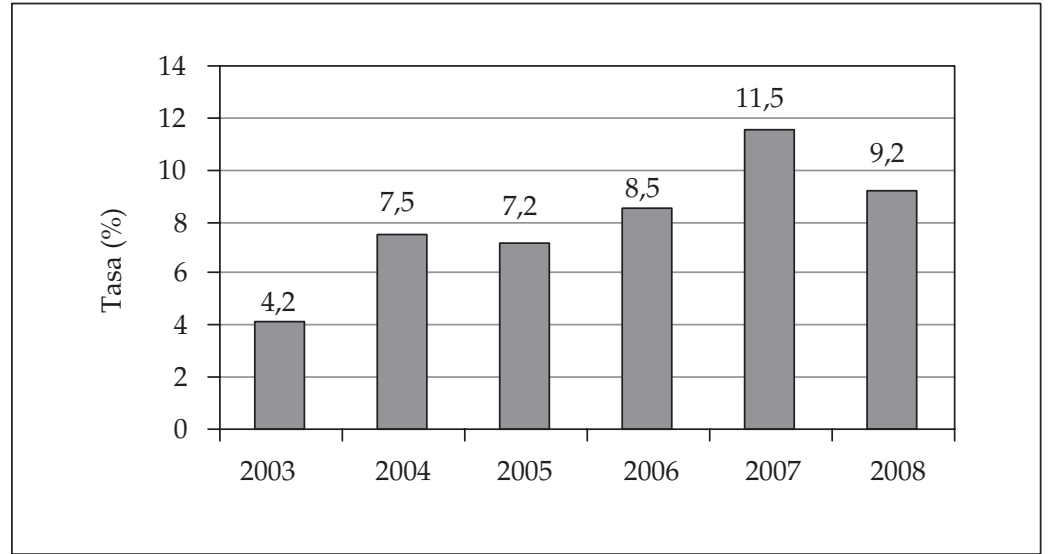

Fuente: Contraloría General de la República.

Gráfico 2: Desempleo e Informalidad 2004-2008

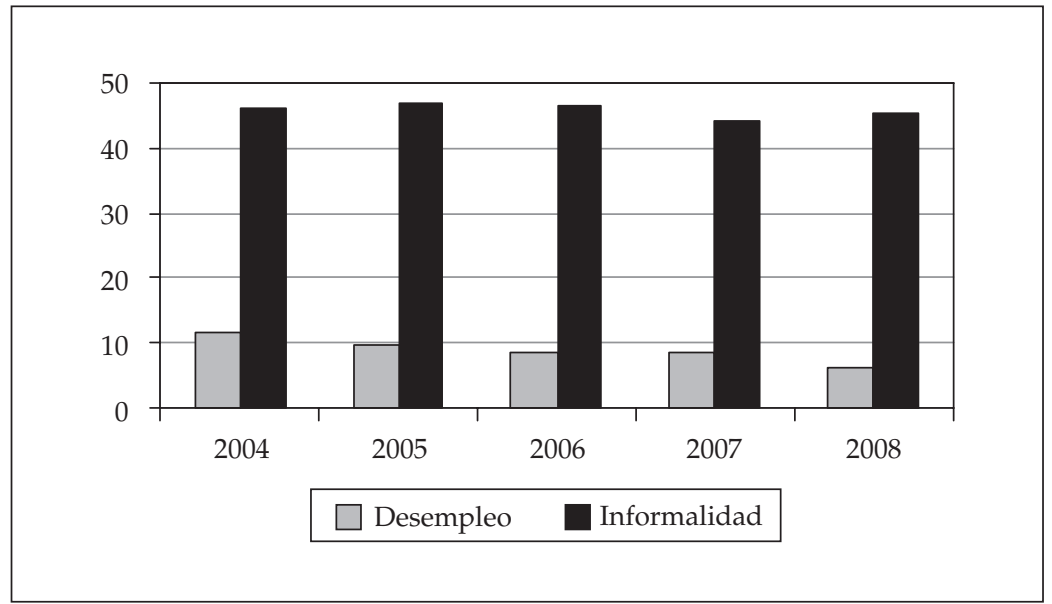

Fuentes: Contraloría General de la República, OIT.

del total de funcionarios prestaron sus servicios en los sectores de Salud, Educación y Seguridad Pública. El valor promedio de la planilla mensual es de alrededor de B/. 128 millones.

El índice de confianza del consumidor panameño ${ }^{1}$ llegó a su punto más bajo en junio cuando se situó en 88,6 puntos (sobre 100). La razón principal de estas fluctuaciones se identifica con la inusual inflación que golpeó a los consumidores. 
Desde 1983 la inflación rondaba el 1\%; es decir, el dinero mantenía su poder adquisitivo de un año a otro. Sin embargo, desde el 2007 la inflación "importada" producto de la revaluación del dólar en los mercados internacionales y de los altos precios de las materias primas ha superado localmente el $4 \%$ (ver Gráfico 3). Los sectores que más contribuyeron a estos incrementos en 2008 fueron los alimentos y bebidas, transporte, vivienda y muebles o equipos para el hogar.

Gráfico 3: Inflación de Panamá 1974-2008

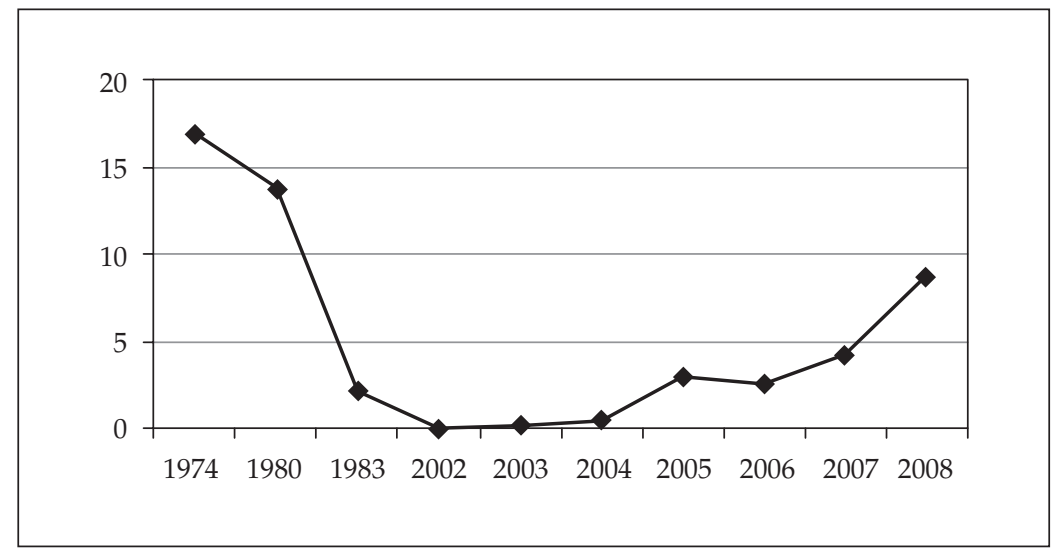

Funte: Contraloría General de la República.

Determinante de los altos precios al consumidor y el productor fue la alta volatilidad en los precios de la energía tanto eléctrica como de los hidrocarburos y la dependencia panameña de la energía proveniente de combustibles. El 2 de enero el precio del barril de petróleo ya rebasaba la cifra histórica de US $\$ 100,00$. En el año se discutieron asuntos como el alto consumo de energía de los panameños y las soluciones al déficit energético del país que incluyen la construcción de hidroeléctricas y refinerías al igual que la interconexión eléctrica centroamericana y de Panamá con Colombia.

El galón de gasolina cruzó la cifra histórica de US\$4,00, lo que tuvo impacto directo en el costo de bienes y servicios. El gobierno nacional, en un intento por paliar la situación, aumentó constantemente los subsidios a los derivados del petróleo, al gas y a la energía eléctrica. Respecto del suministro de combustible, el Estado logró contratar seguros contra la volatilidad en los precios del petróleo, según se anunció en diciembre de 2008, con lo que se contribuiría a evitar una variación drástica del precio de sus derivados durante 2009 y en adelante.

Dado que la mayoría de las empresas productoras y distribuidoras de electricidad son ahora privadas, el control sobre los precios de este rubro es escaso. Apagones y racionamiento por el alto consumo acompañado de protestas contra la construcción de infraestructura hidroeléctrica complicaron el panorama de autonomía energética durante 2008. Sin embargo, en octubre la Autoridad de los Servicios Públicos anunció que la electricidad que Panamá necesita para el período 2011-2022 se había contratado, 
lo que significaría a largo plazo mejores condiciones que las obtenidas hasta el momento, dependiente de contratación a corto plazo.

El balance fiscal del sector público no financiero fue superavitario por tercer año consecutivo, aunque este viene reduciéndose año tras año (ver Gráfico 4). Este desempeño se explica en gran medida por la mayor recaudación fiscal que creció un 5\% especialmente por la reducción de la evasión fiscal que se ha logrado con el Cálculo Alternativo del Impuesto a la Renta (CAIR), aunque también aumentaron los ingresos por contratos de concesión. El total estimado de ingresos del gobierno central fue de B/. 4.598,9 millones, mientras que la deuda pública ronda los US\$20.000 millones distribuidos en cerca de US\$11.000 millones de deuda interna y los restantes US\$ 9.000 millones en deuda externa $(75 \%$ en bonos globales, $15 \%$ con organismos multilaterales, $2,5 \%$ organismos bilaterales y $1,9 \%$ banca comercial, entre otros). ${ }^{2}$

Gráfico 4: Balance fiscal del sector público no financiero 2003-2008

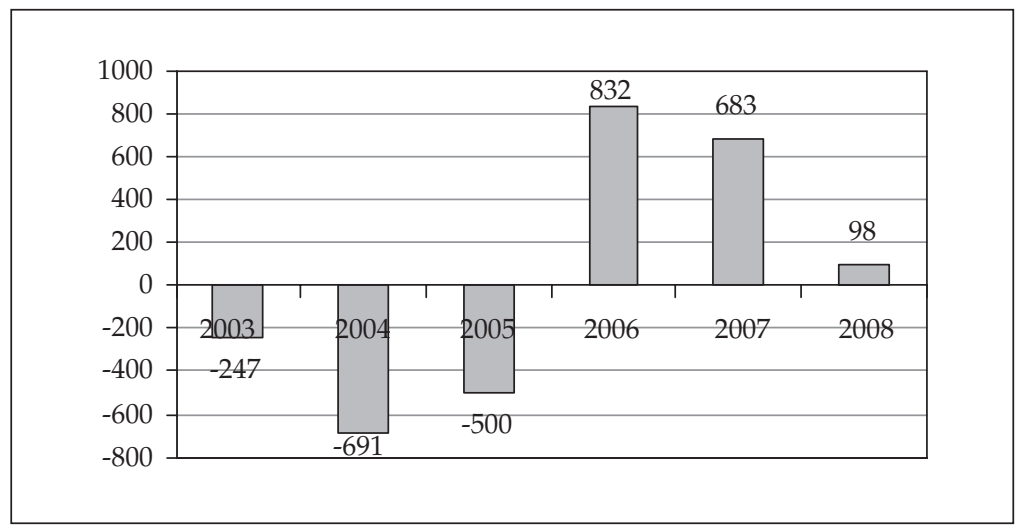

Fuente: Ministerio de Economía y Finanzas.

La balanza comercial de Panamá continuó siendo deficitaria. En 2008 Panamá registró importaciones superiores a las exportaciones de bienes y servicios por valor de 1.350,4 millones. Los factores principales que incidieron en este resultado fueron el aumento del precio de los combustibles líquidos derivados del petróleo, los materiales de construcción y de alimentos como el maíz y el trigo. En respuesta, Panamá continuó profundizando la liberalización de su comercio exterior, mantiene vigentes tratados comerciales con El Salvador, Taiwán, Singapur, Chile y Nicaragua, mientras que esperan por la ratificación de los tratados con Costa Rica, Guatemala, Honduras y el Tratado de Promoción Comercial (TPC) con Estados Unidos. Este último, debido a diferencias políticas entre el Departamento de Estado de ese país y el Ejecutivo y el Legislativo panameño, por la elección de Pedro Miguel González, diputado del gobernante PRD, como Presidente de la Asamblea Nacional 2007-2008. La elección de González, procesado y declarado 
inocente en Panamá por el asesinato del militar estadounidense Zack Hernández, pero señalado por Estados Unidos como responsable, es una de las razones que han esgrimido congresistas estadounidenses para no ratificar el TPC con Panamá, y la explicación más frecuente entre los actores políticos panameños, para explicar su postergación. Sin embargo, se observa que la crítica del Congreso estadounidense, controlado por el Partido Demócrata, al tratado con Panamá, se enmarca en su relación con el Ejecutivo Republicano, en el año previo a las elecciones presidenciales, que ha postergado también la ratificación de otros tratados con países latinoamericanos, con argumentos relacionados a aspectos laborales y medioambientales, entre otros.

En los aspectos comerciales, igualmente relevante al final del año fue la pérdida de los beneficios arancelarios del SGP Plus que otorga la Unión Europea. Panamá no cumplió a tiempo con los nuevos requisitos exigidos para ser incluido en el sistema general de preferencias que cobija a unos 7.200 productos panameños principalmente hortalizas, frutas y manufacturas del mar. Según estimaciones de la Cámara de Comercio, Industrias y Agricultura de Panamá, para el periodo 2009-2011 tendrían que pagarse unos US\$ 60 millones en aranceles para exportar a los países de la Unión Europea.

El motor de la economía panameña continuó siendo la construcción, que en 2008 creció un 30,5\%, siendo éste el tercer año consecutivo de aumento. Las obras de construcción públicas y privadas se concentran en el área metropolitana de Ciudad de Panamá, aunque hay expansión hacia los distritos de Boquete, Chame, Antón, Pedasí, Las Tablas y Chitré. La principal obra pública es la ampliación del Canal de Panamá, aprobada mediante referendo en 2006. La Autoridad del Canal de Panamá fue calificada con grado de inversión A2, lo que le ha permitido encontrar en el mercado financiero fondos a tasas favorables para enfrentar este megaproyecto decisivo para el desarrollo futuro del país. El Banco Europeo de Inversiones, el Banco de Cooperación del Japón, el Banco Interamericano de Desarrollo, la Corporación Financiera Internacional y la Corporación Andina de Fomento prestaron US\$ 2.300 millones al Libor más 5,45\% por un periodo de 20 años con los primeros diez de gracia. En 2008 hubo un promedio diario de 38 buques que cruzaron el Canal de Panamá, dejando ingresos acumulados de US\$1.856,1 millones por concepto de peajes. Aunque disminuyó levemente el tránsito por el Canal, los ingresos no sufrieron bajas dado el aumento de tránsitos de buques tanqueros y cruceros que pagan un peaje más alto.

Según informes de la CEPAL la pobreza disminuyó en 8,1\% entre 2001 y 2007, pasando de $36,7 \%$ de la población a 28,6\%. También hubo una reducción del porcentaje de personas en estado de indigencia que en 2001 era del 19,2\% y en 2007 fue de 11,7\% (ver Gráfico 5), mientras que informes del PNUD indican que Panamá sigue siendo uno de los países más desiguales. Otros indicadores de desarrollo humano para el periodo 2001-2007 muestran avances (ver Gráfico 6).

Otros aspectos de la coyuntura económica incluyeron la fusión de los bancos Uno y Cuscatlán con el Citibank, aprobada el 13 de octubre. En 2008 también se profundizó el proceso de fusión entre Banistmo y HSBC, que unen sus plataformas tecnológicas pero siguen operando bajo insignias comerciales diferentes. En general, el mercado bancario 
Gráfico 5: Pobreza e Indigencia en Panamá 2001-2007

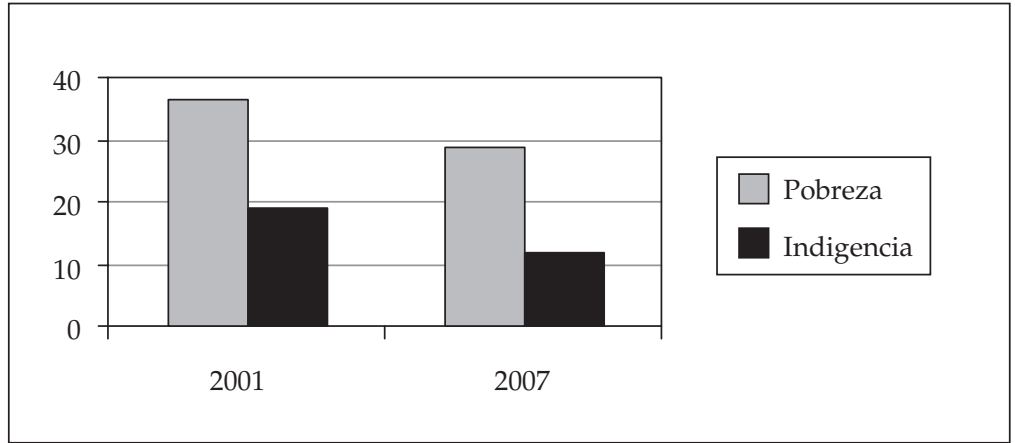

Fuente: CEPAL 2008.

Gráfico 6: Indicadores de Desarrollo Humano en Panamá 2001-2007

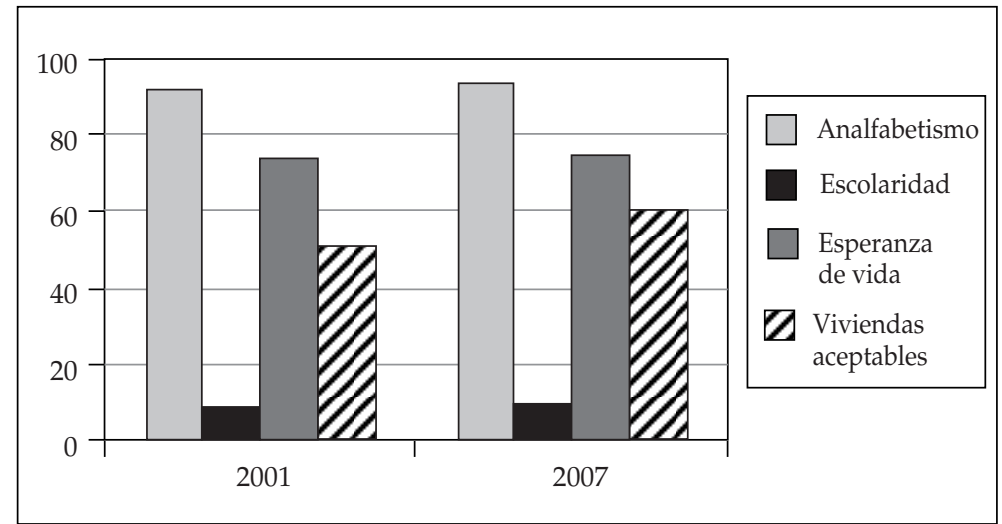

Fuente: INDH, PNUD 2008.

panameño registró un crecimiento cercano al 20\%, movido especialmente por el aumento en la colocación de préstamos destinados al sector industrial, hipotecario, construcción y empresas financieras; ${ }^{3}$ este crecimiento, a pesar de los primeros signos de crisis de liquidez en Estados Unidos y la estabilidad macroeconómica acercaron a Panamá al grado de inversión. ${ }^{4}$ Según la Superintendencia de Bancos de Panamá, al final del año, el sistema bancario panameño refleja fundamentos sólidos y estables caracterizados por altos niveles de liquidez, una solvencia adecuada, salud de la cartera de préstamos y fortaleza en la cuenta de resultados. La principal base de fondos que provee liquidez al sistema proviene de depositantes y clientes particulares (57,6\% del total de pasivos), mientras que los activos líquidos se colocan especialmente en depósitos interbancarios (55\% de la canasta de activos líquidos), tanto en la plaza (15\%) como en el extranjero (40\%). 
Por otro lado, Panamá, que tiene una penetración de telefonía celular del 98\%. En 2008 rompió el duopolio existente entre Movistar y +Móvil, permitiendo, el 14 de mayo, la entrada al mercado a dos nuevos operadores, Digicel y Claro, que comenzaron a operar a partir del 1 de diciembre.

\section{Coyuntura política}

En la arena política el año 2008 estuvo dominado por los procesos electorales internos y la designación de candidatos para las elecciones generales a realizarse en mayo de 2009.

De los 8 partidos legalmente constituidos, 4 realizaron elecciones primarias para designar a sus candidatos a la Presidencia de la República. Algunos de ellos hicieron extensivo este mecanismo para otros cargos como Diputados, Alcaldes, Representantes de Corregimiento, Concejales, e incluso Diputados al PARLACEN. Uno de cada tres panameños se encuentra inscrito en un partido político, cifra que crece con la cercanía de las elecciones (ver Gráfico 7). Para este periodo preelectoral y electoral se romperá la cifra histórica de 2 millones de votantes habilitados de éstos, cerca de 300 mil son jóvenes que podrán votar por primera vez. El 53,23\% de los electores, según el padrón electoral, son menores de 40 años (ver Gráfico 8).

El Partido Vanguardia Moral de la Patria, creado en 2006 tras el segundo lugar obtenido por el ex Presidente Guillermo Endara Galimany en los comicios de 2004, fue el primero en elegir a su candidato; se trata precisamente de Endara, quien participó en las internas como candidato único. Este partido tenía a diciembre de 2008, 35.217 miembros. Las elecciones primarias para la designación del resto de cargos de elección se realizaron el 19 de octubre. Para la alcaldía de la ciudad capital Vanguardia Moral postuló al también ex panameñista, Miguel Batista.

Gráfico 7: Inscritos por partidos constituidos

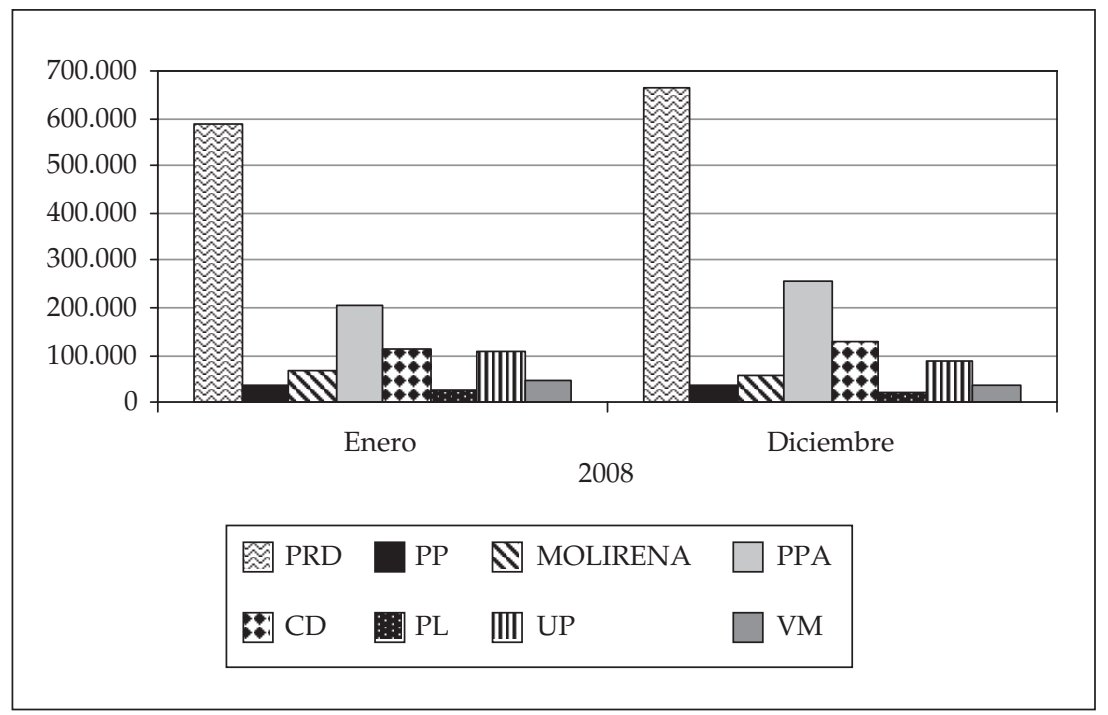

Fuente: Tribunal Electoral. 
Gráfico 8: Distribución etaria de los electores

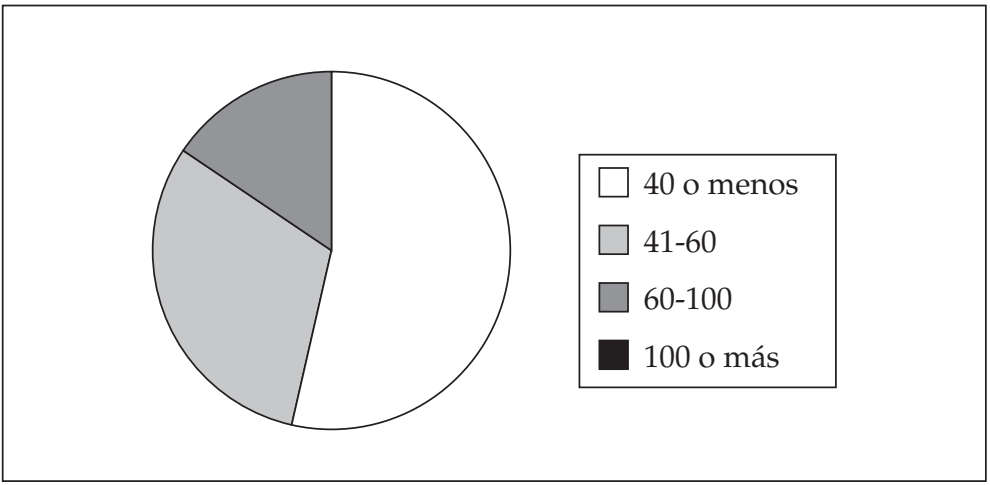

Fuente: Tribunal Electoral 2009.

En los partidos más grandes, Partido Panameñista (PPa) y Partido Revolucionario Democrático (PRD), los primeros procesos de democracia interna que tuvieron lugar fueron la constitución de sus Comités Ejecutivos Nacionales y de los Comités Nacionales de Elecciones, instancias que dan orden, establecen las normas y rigen las elecciones primarias y otros procesos políticos previos a los comicios generales.

En el PPa el año inició con la designación del Comité Nacional de Elecciones, compuesto por 8 miembros encargados de elaborar el reglamento interno para las elecciones primarias. El 26 de abril se realizó el Directorio Nacional del partido, instancia que define las posturas frente a temas de Estado, alianzas con otros partidos y afina detalles de las elecciones internas. Posteriormente fueron postulándose a las primarias para la Presidencia los reconocidos empresarios Marco Ameglio, ex diputado, Juan Carlos Varela, quien además era el Presidente del partido, y Alberto Vallarino, quien en varias oportunidades había sido candidato presidencial, acompañados del médico Jorge Gamboa y otros tres miembros del partido, para un total de 7 candidatos.

En el PPa la disputa no sólo fue por las candidaturas a cargos de elección sino que también estuvo en liza la presidencia del partido que ostentaba Juan Carlos Varela. Tanto sus contrincantes Vallarino y Ameglio, como la ex Presidenta de la República, Mireya Moscoso, le solicitaron en reiteradas ocasiones a Varela que dejara la presidencia del partido mientras participaba en los procesos internos. No obstante él se mantuvo como dirigente máximo del partido. Las elecciones primarias del PPa se realizaron el 6 de julio, proclamándose como ganador y candidato oficial a la Presidencia de la República al ingeniero y empresario Juan Carlos Varela, en contra de los medios que anunciaban la victoria de Vallarino, sobre la base de encuestas mal interpretadas. En este sentido, el incidente debilitó la credibilidad de las encuestas políticas.

El partido panameñista finalizó el año con 257.769 militantes y con gran inestabilidad por la pérdida del apoyo de sus aliados usuales del Movimiento Liberal Republicano, además de fuertes rumores de dimisión de su candidato a la Presidencia, a favor de Ricardo Martinelli que era señalado en las encuestas publicadas como el político opositor con mayores posibilidades de derrotar al PRD. 
En el gobernante PRD, al inicio del año se eligieron los 1.200 delegados al Congreso Nacional del partido, principal instancia de decisión de la colectividad que a través de elecciones oxigena y regenera sus cuadros permitiendo que nuevos competidores ingresen en sus filas. A los delegados les corresponde, entre otras cosas, elegir a los miembros del Comité Ejecutivo Nacional. El octavo congreso nacional del partido se realizó el 9 de marzo, saliendo triunfadores en el apoyo de los delegados, el Alcalde de la Capital, Juan Carlos Navarro, seguido del actual Secretario General del partido y Presidente de la República, Martín Torrijos y, en tercer lugar, la presidenta del partido y ministra de Vivienda, Balbina Herrera. La correlación de fuerzas de éstos y sus aliados marcaron el tono de la contienda por la candidatura única a la Presidencia de este partido.

El primero en postularse como precandidato para la primera magistratura del Estado fue Juan Carlos Navarro, posteriormente hizo lo propio Balbina Herrera. Las postulaciones las completaron el ex ministro de Desarrollo Agropecuario (administración, Torrijos Espino) Laurentino Cortizo y Giovani Solís. Para las primarias el ex Presidente de la República, Ernesto Pérez Balladares, expresó su apoyo al alcalde capitalino, Juan Carlos Navarro, mientras que el Presidente de la República y secretario general del partido, Martín Torrijos Espino, no manifestó públicamente apoyo a ninguno de los 4 precandidatos.

Las elecciones primarias del PRD, partido que a finales del año contaba con 663.249 inscritos, se realizaron el 7 de septiembre, dando como ganadora a la Presidencia de la República a Balbina Herrera, por un estrecho margen de 5\% sobre Juan Carlos Navarro. Tras las primarias y a pesar del discurso de unión, el partido se fracturó al menos en dos bandos, el comandado por la candidata Herrera y el conformado por los seguidores del alcalde capitalino. Este último, hizo fuertes críticas a la política de Seguridad de Martín Torrijos, hecho que profundizó la división, a la vez que dio un ultimátum al partido para que lo designaran como candidato a la Vicepresidencia en la fórmula de Herrera, hecho que se concretó el 26 de noviembre.

Paralelo al proceso de elecciones primarias, en los partidos de oposición el año transcurrió entre rumores de unión y de presentación de candidato único como única posibilidad para ganar al PRD. Los primeros acercamientos públicos los tuvieron Guillermo Endara, de Vanguardia Moral de la Patria, Guillermo "Billy" Ford, de Unión Patriótica, Alberto Vallarino y Mireya Moscoso, del Partido Panameñista. Sin embargo, Juan Carlos Varela insistió en que ese partido presentara un candidato a la Presidencia, vía que mantendría a esa colectividad como una de las más importantes del país.

Durante el período se exploraron alternativas para definir el candidato presidencial único de la oposición, incluyendo la realización de primarias interpartidarias para que los miembros de todos los partidos opositores decidieran el candidato único, o los promedios de las encuestas nacionales a una fecha determinada, pero no hubo consensos al respecto.

En el ala oficialista se concretó la alianza con los pequeños Partido Popular y Partido Liberal, los cuales respaldan la candidatura presidencial de la ingeniera Balbina Herrera 
y presentan listas mixtas para diputados en algunos de los más importantes circuitos plurinominales del país.

Por el lado del Partido Unión Patriótica (UP), su presidente durante el primer semestre del año, Guillermo Ford, condujo las negociaciones con los partidos de oposición; sin embargo, pronto comenzaron miembros del partido a realizar acuerdos "no autorizados" con otros partidos, especialmente Cambio Democrático, para concretar posibles alianzas. Ford se postuló como precandidato a la Presidencia, saliéndole al paso el vicepresidente del Partido José Raúl Mulino. No obstante, Mulino no se postuló como precandidato tras asumir la presidencia del partido a la que renunciara Ford. Honorio Quesada también se presentó como precandidato de dicha colectividad, pero poco antes del Directorio Nacional del partido tanto Ford como Quesada renunciaron a sus aspiraciones. El 19 de julio el partido UP realizó en la ciudad de Penonomé el Directorio Nacional Ordinario y reunión de la Comisión Política Nacional en la que se aprobó la alianza con Cambio Democrático y la postulación a la Presidencia de Ricardo Martinelli. Para los demás cargos de elección, UP realizó el 27 de julio elecciones primarias a las que se presentaron más de 800 miembros que se disputaron los puestos de principales y suplentes para 13 alcaldías y 12 curules en la Asamblea Nacional. Iván Blasser fue escogido como candidato a la Alcaldía de Ciudad de Panamá. No obstante, al final del año había rumores de renuncia de Blasser de sus aspiraciones para que su partido apoyara a un candidato de la alianza por el cambio. El Partido Unión Patriótica contaba con 91.108 adherentes a diciembre de 2008 .

En las toldas del partido Cambio Democrático, a nivel de candidatos a la Presidencia de la República no hubo ninguna sorpresa en 2008. El fundador del partido, Ricardo Martinelli, desde su participación en 2004 en la contienda por la primera magistratura del Estado había anunciado su intensión de volver a postularse para llegar al Palacio de las Garzas. El acto oficial de inscripción de la precandidatura se realizó el 16 de junio, siendo candidato único por su partido. Este partido, que en las encuestas se encuentra en segundo lugar de simpatía, no logró postular miembros a cada uno de los más de 700 cargos de elección que se encuentran en disputa. Las elecciones primarias previstas para el 5 de octubre fueron adelantadas para el 3 de agosto dada la premura en la realización de comicios en los otros partidos. 131.663 personas se encontraban inscritas en este partido a diciembre de 2008.

El Movimiento Liberal Republicano (MOLIRENA) finalizó 2008 con 59.002 miembros. A mediados del año la sede oficial del partido fue embargada a raíz de la demanda que interpusiera el ex presidente del partido, Jesús "Maco" Rosas, por compromisos financieros de los cuales fue fiador durante su gestión, pero que no fueron honrados por la colectividad. El 27 de julio este partido realizó su Convención Provincial Nacional en la que se escogió la nueva Junta Directiva. El 16 de septiembre este partido y el también opositor Panameñista consolidaron una alianza que fue ratificada el 23 de noviembre, no obstante, antes de finalizar el año el MOLIRENA le solicitó a Juan Carlos Varela que desistiera de su candidatura para dar paso a una gran alianza, en aras del cambio, encabezada por su rival Ricardo Martinelli. 
Se observa que uno de los distintivos de esta campaña ha sido el uso intensivo de encuestas. Desde mayo de 2008 varias firmas encuestadoras iniciaron el monitoreo de la intensión de voto de los precandidatos y luego candidatos oficiales a la presidencia (ver Gráfico 9).

Gráfico 9: Intención de voto a la Presidencia

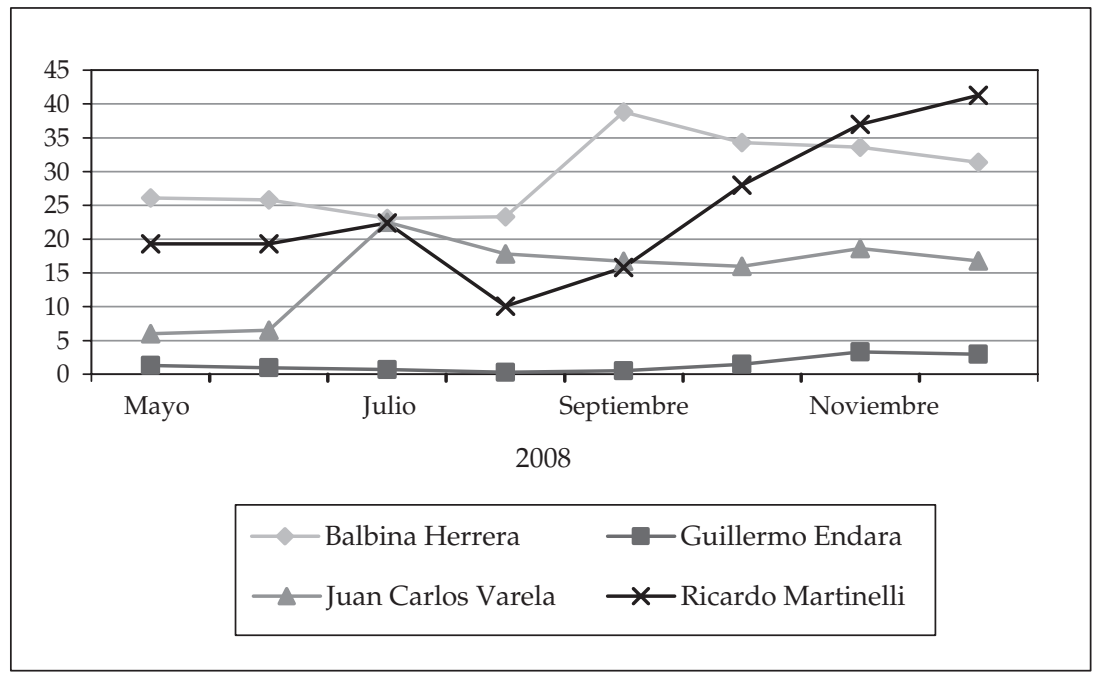

Fuente: Encuesta Dichter \& Neira Panamá.

El tono de la larga campaña hacia la Presidencia de la República ha sido preponderantemente negativo, primero a través de internet y luego con el uso de medios tradicionales de comunicación.

Durante las primarias del gobernante Partido Revolucionario Democrático, la precandidata Balbina Herrera denunció a Juan Carlos Navarro ante el Tribunal Electoral, por utilizar su imagen sin consentimiento para propaganda electoral descalificadora, en la que se recordaba el compromiso público previo de Herrera, de apoyar la candidatura de Navarro y la supuesta falta a la palabra empeñada consiguiente. El Tribunal Electoral se pronunció el 13 de agosto ordenando la suspensión de la transmisión de los avisos pautados, hecho que suscitó discrepancias entre políticos y comunicadores por considerar la medida restrictiva de la libertad de expresión. ${ }^{5}$ Herrera luego desistió formalmente de la denuncia.

De forma semejante, la campaña de Juan Carlos Varela solicitó la suspensión de un aviso pautado realizado por la campaña de Ricardo Martinelli, en la cual se le atacaba como una "cara nueva con huesos de un político viejo". El Tribunal Electoral dejó sin efectos sus resoluciones anteriores y consideró que los avisos podían ser transmitidos sin ningún inconveniente. 
Cabe resaltar que hasta el 31 de diciembre de 2008 los candidatos a la Presidencia de la República no habían firmado, como era ya tradición, un pacto ético electoral convocado por la Iglesia Católica, en el que se comprometieran a no usar recursos públicos para proselitismo político, a no realizar campañas negativas y a realizar un debate público de altura y con base en ideas, entre otros aspectos.

Las decisiones del Tribunal Electoral de tolerar el discurso descalificador y la falta de compromiso de suscribir el pacto ético electoral (consecuencia de la negativa de Martinelli de subscribirlo) dieron el marco para el tono de la campaña electoral de 2009.

Otro de los hechos que marcaron la política panameña en 2008 de cara a las elecciones generales del próximo año fue la demanda por inconstitucionalidad del Código Electoral presentada por dos ciudadanos que aspiraban bajo la figura de la libre postulación a la Presidencia de la República. Se trata de Juan Manuel Castulovich (diplomático) y Juan Jované (profesor universitario y ex Director de la Caja del Seguro Social), quienes alegaron que la Constitución no prohíbe la libre postulación presidencial, mientras que el Código electoral exige que los candidatos a Presidente sean postulados por partidos políticos legalmente reconocidos.

Actualmente, en Panamá pueden presentarse bajo la figura de la libre postulación Diputados, Alcaldes, Representantes de Corregimiento y Concejales. El 22 de diciembre el Tribunal Electoral rechazó la candidatura de Jované.

Sin embargo, el profesor Jované interpuso un recurso ante la Corte Suprema de Justicia para que se pronuncie sobre este caso. La jurisprudencia constante de la Corte Suprema de Justicia ha señalado desde principios de los años ochenta que la Constitución refiere a la Ley la determinación de los cargos que admitirían la libre postulación.

Por otro lado, 2008 fue un año socialmente muy complejo. Varios escándalos de corrupción, especialmente el caso FECE (Fondo de Equidad y Calidad de la Educación), el robo de las esculturas de Bronce "Juegos de Antaño" y contratos con sobrecostos inexplicables para la remodelación de "Escuelas Rancho" y la remoción de fibra de vidrio de los planteles educativos, empañaron la gestión del gobierno central.

El 20 de octubre de 2008 se dio el que probablemente fue el escándalo que más directamente afectó a la administración durante 2008. Ese día un diario de la localidad denunció que el ministro de Gobierno y Justicia, Daniel Delgado Diamante, había asesinado a un subalterno, cuando servía en la Guardia Nacional, en 1970. Eventualmente, la discusión pública del caso desembocó en el reemplazo de Delgado Diamante, artífice de la reforma de los aparatos de seguridad del Estado, que debían servir para relanzar la seguridad pública durante 2008.

Reflejo probable del desgaste ocasionado por estos casos y otras circunstancias es la baja aprobación de gobierno (41 puntos, teniendo como media latinoamericana 52 puntos) y la baja confianza (25 puntos, con un promedio latinoamericano de 44) que registró para Panamá el Latinobarómetro 2008 (ver Gráfico 10). En el mismo sentido, el Índice de Percepción de la Corrupción 2008 de Transparencia Internacional para Panamá muestra un nivel muy bajo de sólo 3,4 en una escala de 10. Este resultado es incluso inferior al 
que obtuviera Panamá en el último año de la administración de Mireya Moscoso cuando se obtuvo 3,7.

Gráfico 10: Confianza y Aprobación del Gobierno de Panamá

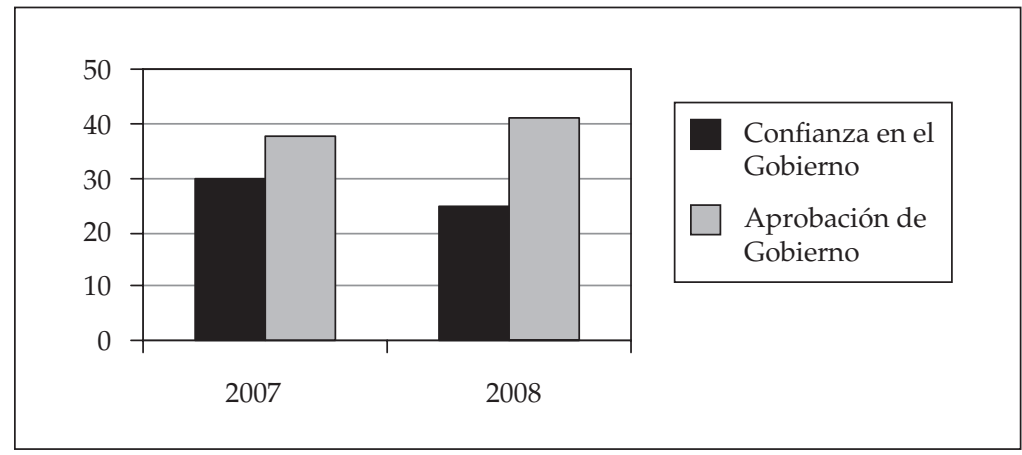

Fuente: Latinobarómetro.

Asimismo, los ciudadanos criticaron la inacción del gobernante frente a temas tan cruciales como la calidad de la educación, el transporte público de la ciudad capital, la salud y la seguridad pública. En relación con este último, a mediados de año el Presidente obtuvo de la Asamblea poderes especiales para legislar mediante decreto; pocos días después en Consejo de Gabinete aprobó la creación de cuatro estamentos de seguridad y reestructuración del Sistema de Protección Institucional.

Los decretos-ley de seguridad, como fue conocido este paquete de reformas, pronto encendieron las alarmas de un sector importante de la sociedad civil y de los partidos políticos de oposición, por la creación del Servicio Nacional de Inteligencia y Seguridad (SENIS) con poderes que aparentemente violaban la Constitución, por los privilegios que obtendrían los miembros de las nuevas instituciones (estabilidad en el cargo, seguros de vida, bonificaciones por antigüedad, asistencia médica, entre otros) y por la exclusión del régimen ordinario de contrataciones públicas "Panamá Compra". Las protestas se extendieron por varias semanas al final de las cuales los decretos fueron aprobados por el Ejecutivo sólo excluyendo los artículos más controvertidos que comprometían derechos fundamentales, para que fueran discutidos y aprobados por el Legislativo. No obstante, organizaciones de la sociedad civil presentaron una querella criminal contra los ministros del Gabinete, reclamaron a los candidatos a comprometerse a derogar los decretos de llegar a la Presidencia y demandaron los decretos por inconstitucionales, fundamentalmente por autorizar la dirección de los organismos de seguridad a personal uniformado (en contraste a la regulación vigente, que dispone que sean civiles).

En otros aspectos políticos, durante 2008 el Estado panameño fue sometido a un proceso de reestructuración con el fin de buscar eficacia y más calidad en la prestación de servicios públicos básicos. Los cambios más importantes incluyeron la creación de dos nuevos viceministerios de Seguridad y de Gobierno, en el Ministerio de Gobierno y Justicia, y Académico y Administrativo en el Ministerio de Educación; la creación del 
Servicio Nacional de Frontera, el Servicio Nacional Aeronaval (unión del Servicio Aéreo Nacional y del Servicio Marítimo Nacional), la Autoridad de Turismo de Panamá y el Instituto Nacional de la Mujer.

En seguimiento a los acuerdos de la Concertación Nacional para el Desarrollo convocada por el gobierno nacional en 2006, se creó mediante aprobación de Ley la institución para hacer seguimiento de manera sistemática y periódica a los acuerdos sobre el futuro de desarrollo del país. Si bien Panamá tiene una tradición de diálogos y concertación para la definición de aspectos estructurantes del desarrollo, este último ejercicio prospectivo se distingue por la creación de una entidad compuesta por 21 sectores representativos de la sociedad que hará seguimiento al Plan de Desarrollo que se nutre de los recursos generados por el Canal.

\section{COYUNTURA SOCIAL}

El eje articulador de la mayoría de las protestas sociales en 2008 fue el alto costo de la vida y la pérdida de poder adquisitivo de los panameños; no obstante, algunas decisiones y hechos sectoriales también generaron la movilización de grupos organizados de la sociedad civil y de los más importantes sindicatos panameños.

Constantes paros a las actividades que realizan los profesionales de la salud se dieron a lo largo del año. Los gremios de la salud, a pesar de haber conformado junto con el gobierno nacional una comisión para expedir una Ley que unifique el sistema, salieron a las calles para oponerse a dicho proyecto. Desde su punto de vista, el proyecto de Ley no contemplaba las fuentes de financiación del sistema y abría las puertas para la privatización de ciertos servicios. Actualmente, el sistema público de salud está dividido entre el Ministerio de Salud, que atiende a las personas subempleadas y a los desempleados, y la Caja del Seguro Social, que brinda servicios a los cotizantes (trabajadores formales) y sus beneficiarios. Igualmente continuaron las presiones y las protestas de los afectados por envenenamiento con el Dietileneglycol. Las protestas se centraron en el trato que reciben de las instituciones prestadoras de servicios de salud; la falta de indemnización por las víctimas mortales y la expedición de incapacidad e indemnización a los enfermos, y por el retraso en los fallos que esclarezcan cómo una sustancia química utilizada en la industria como refrigerante se utilizó para la elaboración de medicamentos en los laboratorios de la Caja de Seguro Social.

En el sector educativo las protestas tuvieron como detonante la contaminación por fibra de vidrio en las escuelas, el incremento de la violencia y la inseguridad en los alrededores de las instalaciones educativas pero, especialmente, la propuesta del Ejecutivo de reformar la Ley Orgánica de Educación para introducir instrumentos de fiscalización del desempeño docente. A esta propuesta, la Asociación de Profesores de Panamá (ASOPROF) se opuso férreamente, contando con el apoyo de otros gremios que conforman el Frente Nacional por la Defensa de los Derechos Económicos y Sociales (FRENADESSO). 
2008 también fue un año turbulento para el sector transportista, especialmente en el área metropolitana de la ciudad capital. El primer episodio data de enero cuando dos gremios de transportistas proponían un subsidio al precio del diesel, mientras que otros buscaban una revisión de las tarifas del servicio. La petición de ambos convergía en el alto costo de los carburantes que debía extenderse al costo de los pasajes; no obstante, el gobierno nacional y los ciudadanos se opusieron a cargar los incrementos a los usuarios, hecho que habría disparado la inflación. La estrategia del gobierno contempló aumentar los subsidios que reciben los transportistas, reglamentar la ley de transporte público de pasajeros pero, adicionalmente, introducir un cambio en el sistema de transporte urbano masivo. El 8 de mayo fue presentado el "Plan de Movilidad Urbana y Modernización del Transporte" conocido como "transmóvil". Este plan buscaba reemplazar definitivamente los autobuses urbanos, denominados popularmente como "Diablos Rojos", por nuevas unidades que brinden seguridad y comodidad, superando el modelo actual de prestación del servicio basado en intermediarios en el transporte que administran cupos individuales.

No obstante, este anuncio incrementó las protestas del sector transportista que se siente amenazado, y de los usuarios, organizados bajo el liderazgo del Movimiento 23 de Octubre $^{6}$ (ahora con personería jurídica), que no evidencia que el nuevo sistema propenda por la dignidad, la calidad y la eficiencia a precios razonables.

Otro sector que constantemente se manifestó en 2008 fue el de jubilados. Los adultos mayores recurrieron al cierre de importantes vías en la Ciudad de Panamá para protestar por el alto costo de la canasta básica, el desabastecimiento de medicinas y la calidad de la atención en salud. Las demandas de este grupo fueron atendidas por el gobierno nacional con beneficios extraordinarios que sumaron US $\$ 85,00$, otorgados en forma de bonos dos veces al año.

En el interior del país y en las zonas rurales, las principales movilizaciones las protagonizaron los arroceros y otros productores agobiados por los altos costos de los insumos agrícolas, los bajos precios de compra de sus productos, la competencia (en su opinión desleal) del Estado por la venta de productos "compita", la limitación a las exportaciones de arroz y la pérdida de las preferencias arancelarias del SGP-Plus.

Pero, sin lugar a dudas, el principal conflicto social registrado en 2008 fue el desarrollado tras la muerte del obrero All Iromy Smith Rentería, el 12 de febrero, durante una manifestación del Sindicato Único Nacional de Trabajadores de la Construcción y Similares (SUNTRACS) en Colón, contra el alto costo de la vida. La muerte del joven de 29 años se produjo cuando la policía antimotines trataba de dispersar, con gases lacrimógenos y perdigones, la protesta que estaba bloqueando la carretera que comunica a Colón con Ciudad de Panamá. Los días siguientes, 13 y 14 de febrero, hubo grandes manifestaciones que se tornaron violentas. Dada la gran cantidad de proyectos de edificios habitacionales en varios sectores de la capital, los obreros de la construcción lograron paralizar las

6 El Movimiento 23 de Octubre, conformado a raíz del incendio de un bus urbano en el que murieron calcinadas 18 personas en 2006, tiene como objetivo luchar por la mejora del sistema de transporte colectivo. 
principales vías en Ciudad de Panamá con réplicas a menor escala en ciudades del interior de la República. Por algunos momentos eran más los sindicalistas amotinados que los agentes de la policía disponibles para hacerles frente. Propiedades privadas, vehículos particulares y de transporte público y mobiliario urbano fueron vandalizados.

Al movimiento de protesta se unieron otros gremios sindicalizados como los maestros, los transportistas y algunos operadores del sistema público de salud agrupados en FRENADESSO, además de los familiares de los envenenados con Dietileneglycol, que presionaron al gobierno del Presidente Torrijos con un pliego de 10 peticiones entre las que resaltaban la aprobación del reglamento de seguridad en construcciones, congelar los precios de la canasta básica, la libertad inmediata de los detenidos en los disturbios, el fin de la represión a los manifestantes y la destitución del ministro de Gobierno y Justicia y del director de la Policía. Entre la ciudadanía, los partidos políticos y la empresa privada había voces de apoyo a las instituciones, especialmente la Policía, y la autoridad del Ministro de Gobierno y Justicia y el Presidente de la República, pero también hubo quienes criticaron la actitud beligerante del gobierno y la fuerza desmedida para reprimir a los manifestantes. Para finales de febrero, el Reglamento de Seguridad de la Construcción había sido sancionado sin que se incorporaran todas las peticiones de SUNTRACS.

En los meses siguientes nuevas marchas de FRENADESSO se dirigieron a la Presidencia de la República reclamando una comisión de diálogo con representantes del Ejecutivo para tratar temas de derechos humanos, seguridad en la construcción, justicia, aumento general de sueldos, el alto costo de la vida, seguridad alimentaria y la reparación urgente de escuelas públicas, entre otros.

Los indicadores sobre seguridad pública continuaron deteriorándose durante 2008, al punto que la agenda política tanto a la interna de los partidos políticos como entre ellos, y entre la sociedad y el Estado, estuvo marcada intensamente por las iniciativas para contrarrestar la delincuencia, en especial la delincuencia organizada, y la percepción de ineficacia de los aparatos policiales y judiciales en la represión del delito.

Pero no todas las movilizaciones sociales que se dieron en 2008 fueron de protesta social; el país entero vibró de emoción el 18 de agosto con el salto del "canguro colonense", Irving Saladino, que el obtuvo la medalla olímpica de oro en los Juegos de Beijing, en salto largo con una marca de 8,34 metros. Su recibimiento en Panamá, días después, fue un verdadero carnaval a pesar de la lluvia. Con lágrimas en los ojos, Saladino, junto al ex boxeador panameño Roberto "Mano de Piedra" Durán, y el Director del Instituto Panameño de Turismo, Rubén Blades, entonaron las letras de la canción "Patria", de autoría de Blades, removiendo las fibras más sensibles de los panameños presentes en el evento y televidentes por cadena nacional.

Meses más tarde, la joven artista Margarita Henríquez, oriunda de La Villa de los Santos, al interior del país, se disputaba a nivel continental en el "reality show" Latin American Idol. La movilización de los panameños y su solidaridad con la "causa" de Margarita, le permitieron obtener los votos (onerosos mensajes de texto) para vencer a su rival costarricense. La reflexión consiguiente sobre este fenómeno de masas enfocó tanto en 
el reconocimiento al joven talento nacional como en la manipulación mediática a cargo de las empresas televisoras y telefónicas, que reportaron ingresos millonarios a cargo del apoyo de miles de panameños a la cantante.

\section{COYUNTURA SUBREGIONAL E INTERNACIONAL}

En febrero Panamá asumió la presidencia del Consejo de Seguridad de la ONU, mes en el que la agenda estuvo centrada sobre África y Medio Oriente.

El Presidente Martín Torrijos realizó viajes a Qatar, donde acordó abrir una embajada, a Cartagena (Colombia) para participar de la Cumbre Regional de Drogas, Seguridad y Cooperación, ocasión en la que también selló con Colombia un acuerdo de interconexión eléctrica; y a Brasil, para participar de la Cumbre de América Latina y el Caribe.

Se registraron las visitas del Presidente Felipe Calderón de México (5 de marzo) que acudió a Expocomer y anunció la eliminación del requisito de visa para los panameños que ingresan a ese país; del Presidente Tabaré Vásquez de Uruguay (16 de junio) para firmar acuerdos de cooperación comerciales y culturales; del Presidente Ma Ying-Jeou de Taiwán (13 de agosto), país que donó equipos para la Policía Nacional de Panamá valorados en US\$ 3 millones. También estuvo de visita la Primera Dama de Estados Unidos, Laura Bush (20 de noviembre), quien firmó la "Alianza de las Américas para la Concienciación e Investigación sobre el Cáncer de Mama" y fue actualizada sobre el impacto del programa "English for life" que financia su gobierno en Panamá.

Durante el mes de septiembre, la Universidad de Panamá le otorgó al Presidente Evo Morales el doctorado "Honoris Causa". El rector de la Universidad, Gustavo García de Paredes, indicó que el reconocimiento se debía a que Morales, a pesar de ser muy humilde, se convirtió en presidente para resolver problemas que son congénitos en la historia de Bolivia. En su visita el presidente boliviano también se reunió con Martín Torrijos para firmar acuerdos para profundizar las relaciones económicas, políticas, científicas, educativas y jurídicas.

En diciembre, visitaron Panamá Cancilleres, Ministros de Relaciones Exteriores y de Comercio de doce países para realizar el encuentro "Caminos para la Prosperidad en las Américas", promovido por el Presidente de Estados Unidos, George Bush. Al encuentro acudió Condoleezza Rice, Secretaria de Estado de Estados Unidos, que previamente se había reunido con el Presidente Torrijos para tratar temas de narcotráfico, el Canal de Panamá y el Tratado de Promoción Comercial (TPC).

En 2008 varios organismos internacionales decidieron establecer sede oficial en Panamá. Entre ellos, la Secretaría Técnica para Personas con Discapacidad de la OEA, el Centro del Agua del Trópico Húmedo para América Latina y el Caribe (CATHALAC), el Centro Logístico Humanitario para América Latina y el Caribe y el depósito de ayuda humanitaria del Programa Mundial de Alimentos.

En marzo entró en vigencia el TLC con Chile que reduce a 0 los aranceles del 93\% de los productos panameños que llegan al país austral. Para el mes de julio se habían finalizado 
las conversaciones para la suscripción de un tratado de libre comercio con Canadá. Con relación al TLC de Centroamérica con Panamá, en 2008, Costa Rica aprobó el tratado y firmó el protocolo bilateral con Panamá, lo que le permite a dicho país exportar con menores costos los cerca de 1.500 productos que actualmente comercializa. Costa Rica es el primer mercado de las exportaciones panameñas y cuarto proveedor de mercancías e insumos a Panamá. Posteriormente, Panamá aprobó el protocolo bilateral con Guatemala, país en el que el TLC todavía se encuentra en proceso de ratificación. Antes de finalizar el año se firmó el protocolo bilateral del tratado entre Panamá y Honduras. También se avanzó en la integración del mercado bursátil panameño, costarricense y salvadoreño.

En cuando a las relaciones fronterizas, pobladores del límite con Colombia notificaron de varias incursiones de grupos armados ilegales, la mayoría de ellos identificados con distintivos de la guerrilla de las FARC. El gobierno panameño desestimó la mayoría de estas incursiones bajo su política de neutralidad frente al conflicto colombiano. Sin embargo, el 26 de febrero un grupo de seis presuntos guerrilleros a bordo de una embarcación en aguas territoriales panameñas se enfrentó a tiros con agentes de la Policía Nacional que los capturó. Los sindicados, que aceptaron pertenecer al Frente 57 de las FARC, aparentemente estaban transportando drogas en la embarcación en la que se hallaron rastros al realizar pruebas de laboratorio. Hasta finalizar el año, estas seis personas se encontraban recluidas en centros carcelarios panameños.

El 29 de mayo un trágico evento marcó la relación bilateral de Panamá con Chile. Un helicóptero del Servicio Aéreo Nacional (SAN) cayó sobre el céntrico sector comercial de Calidonia, en Ciudad de Panamá, muriendo dentro 11 de sus 12 ocupantes, entre los que se encontraban el Director de Carabineros de Chile, General José Alejandro Bernales, su esposa Teresa Bianchini y cuatro altos mandos chilenos más. El resto de los ocupantes eran policías panameños. Desde ese momento, las investigaciones sobre las causas del siniestro, la supuesta falta de mantenimiento de las aeronaves del SAN, la fiabilidad de la investigación realizada localmente y el monto de las indemnizaciones a los familiares fueron el centro del tenso diálogo entre ambos países. El informe final determinó que un error humano del piloto Juan Delgado, que no supo gestionar la emergencia fue la causa del accidente; sin embargo, el único sobreviviente, copiloto del helicóptero insistió en que las fallas fueron mecánicas.

En materia de derechos humanos, en 2008 Panamá fue encontrada culpable por la Corte Interamericana de Derechos Humanos de la OEA por la desaparición forzada del dirigente Heliodoro Portugal, hecho ocurrido en 1970 durante la dictadura militar. Panamá fue condenada a pagar una reparación económica de US\$226.000 a los familiares de las víctimas por el daño emergente patrimonial familiar y el lucro cesante sufridos por los hijos y la madre de la víctima, además, a publicar en un diario oficial y otro de amplia circulación nacional la sentencia completa de la CIDH, a realizar un acto público de reconocimiento internacional de la responsabilidad por violación a los derechos de la víctima. El fallo establece que el Estado panameño violó el derecho a la integridad personal, la protección y garantías judiciales de Heliodoro Portugal, quien fue detenido y luego desaparecido, así como que el Estado no garantizó un verdadero acceso a la 
justicia a los familiares dentro de un plazo razonable, para el esclarecimiento de los hechos, la investigación y la sanción de todos los responsables.

Por último, durante el año hubo incertidumbre por la posible repatriación del ex dictador Manuel Antonio Noriega, quien se encuentra detenido en Estados Unidos pero que además ha sido pedido en extradición por Francia, donde fue hallado culpable de lavado de dinero y condenado a 10 años de cárcel. En Panamá sus propiedades entraron en proceso de subasta, a pesar de los alegatos de Noriega de que éstas habían sido adquiridas legalmente con su dinero y que otras las había recibido como herencia. El proceso de extradición fue suspendido hasta que finalizara la fase de apelaciones en el Tribunal en la Florida, cuya vista judicial fue pospuesta para enero de 2009.

\section{Cambios Institucionales-Cambios sustanciales de Políticas Públicas}

\section{a. Creación y Reforma de Instituciones}

Se crearon las siguientes instituciones: la Autoridad de Aduanas, ${ }^{7}$ Servicio Nacional de Migración ${ }^{8}$ y Autoridad de Turismo de Panamá en reemplazo de entidades equivalentes, de menor jerarquía institucional: Dirección General de Aduanas, Dirección Nacional de Migración e Instituto Panameño de Turismo. Se modificaron también instituciones como la Superintendencia de Bancos. ${ }^{10}$

También se crearon dos nuevos viceministerios de Seguridad y de Gobierno, en el Ministerio de Gobierno y Justicia, y Académico y Administrativo en el Ministerio de Educación.

Más significativos resultan los cambios operados en la institucionalidad de la seguridad pública. Así, hubo cambios en la Policía Nacional, ${ }^{11}$ Servicio de Protección Institucional, ${ }^{12}$ y Consejo de Seguridad Pública y Defensa Nacional, ${ }^{13}$ y se crearon además el Servicio Nacional Aeronaval, ${ }^{14}$ el Servicio Nacional de Fronteras, ${ }^{15}$ y el Servicio Nacional de Defensa y Seguridad. ${ }^{16}$

\section{b. Cambios legales y reglamentarios}

Hubo una importante y general reforma del régimen jurídico de la actividad marítima, a través del paquete de leyes sobre comercio marítimo (Ley 55 de 2008), sobre puertos (Ley 56 de 2008) y sobre marina mercante (Ley 57 de 2008).

\footnotetext{
Decreto Ley 1 de 2008. Decreto Ley 3 de 2008

Decreto Ley 4 de 2008.

Decreto Ley 2 de 2008.

Decreto Ley 5 de 2008.

Decreto Ley 6 de 2008

Decreto Ley 9 de 2008.

Decreto Ley 7 de 2008.

Decreto Ley 8 de 2008.

Decreto Ley 9 de 2008.
} 


\section{c. Cambios sustanciales en Políticas Públicas}

El Programa de Desarrollo Comunitario para Infraestructura Pública (PRODEC) cuyo objetivo principal es la identificación y planificación de proyectos de inversión a nivel nacional que amplíen el desarrollo del capital humano de las comunidades beneficiadas, continuó ejecutándose. ${ }^{17}$ En un ejercicio de participación ciudadana, los miembros de la comunidad le comunican al Presidente de la República y a sus ministros, ante las autoridades locales y público en general, las prioridades de los habitantes.

A inicios de 2008 el salario mínimo fue ajustado a US\$ 320,00, sin embargo, para los panameños con estos ingresos la Canasta Básica de Alimentos representó alrededor del $75 \%$. Durante el año se discutió en la Asamblea Nacional la posibilidad de indexar los salarios a la inflación, pero la propuesta de Ley no prosperó. No obstante, el gobierno aprobó bonos para los pensionados que al final del año sumaron B/. 85 y aumentó el aporte a la familias vinculadas a la Red de Oportunidades a B/. 50. Otra respuesta gubernamental a los altos precios fue el programa de productos y servicios "Compita" que son empacados y distribuidos directamente por el Estado con valores de venta controlados. Los principales productos "compita" son el arroz, aceite, azúcar, sal, café, harina, sardinas, pero también se vendieron para Navidad jamones, pavos y dulces. Adicionalmente, fue aprobada la reducción del impuesto sobre la renta a los contribuyentes de ingresos medios (entre US\$ 800,00 y US\$ 860,00) como forma de inyectar liquidez en la economía e incentivar el consumo.

\section{Resultados de Elecciones}

No hubo procesos electorales nacionales o locales, durante 2008.

Varios dirigentes sindicales han saltado a la arena política tanto por los partidos políticos como por la vía de la libre postulación que a partir de los próximos comicios está permitida por el Código Electoral. Priscila Vásquez, dirigente de la Asociación Nacional de Empleados de la Caja del Seguro Social (ANFACSS) aspira a ser diputada sin que en su postulación medien partidos políticos, mientras que el dirigente magisterial Efraín de León se ha presentado a través del Partido Panameñista.

El Código Electoral establece una cuota de 30\% de las candidaturas a cargos de elección para las mujeres, cuota que no es obligatoria y que no acarrea sanciones para los partidos que la incumplan. Datos preliminares de las postulaciones por los partidos políticos dan muestra de una disminución en el acceso de las mujeres a las candidaturas, lo que repercutirá en una menor representación a todo nivel en las elecciones generales de mayo de 2009. 


\section{Poder Ejecutivo}

\section{a. Composición y rotación del Gabinete}

Aunque el PRD concurrió a las elecciones de 2004 en alianza con el PP, la mayoría del Gabinete es miembro del PRD. Tras los cambios de julio, sólo el Segundo Vicepresidente y un Viceministro (MIDA) son miembros del PP.

\section{i. Composición del Gabinete y Rotación en altos cargos públicos}

De acuerdo al código electoral panameño, los altos funcionarios del gobierno que aspiren a puestos de elección popular deben renunciar al menos 6 meses antes de la fecha de la elección para no ser inhabilitados. Por este motivo, varios ministros, viceministros y directores de entidades descentralizadas dejaron en 2008 sus cargos. También cabe resaltar la salida del Ministro de Educación, Belgis Castro, y del Ministro de Gobierno y Justicia, Daniel Delgado.

Los nuevos integrantes del gabinete en el año 2008 fueron:

\begin{tabular}{|c|c|c|c|}
\hline Cargo & Nombre & Partido & Profesión/Ocupación \\
\hline Viceministro de Vivienda & José Batista & PP & Arquitecto \\
\hline Viceministra Académica (Educación) & Mirna Vallejos de Crespo & PRD & $\begin{array}{l}\text { Educadora, Lic. en } \\
\text { Matemáticas y Física }\end{array}$ \\
\hline $\begin{array}{l}\text { Viceministro Administrativo } \\
\text { (Educación) }\end{array}$ & José Pío Castillero & PRD & Abogado \\
\hline Viceministro de la Presidencia & Carlos García & PRD & Economista \\
\hline Viceministro de Comercio Exterior & Severo Sousa & Ninguno & Empresario \\
\hline Ministro de Vivienda & Gabriel Diez & PRD & Ingeniero, empresario \\
\hline Ministro de Educación & Salvador Rodríguez & PRD & $\begin{array}{l}\text { Ex Rector UTP, } \\
\text { Ingeniero civil }\end{array}$ \\
\hline $\begin{array}{l}\text { Viceministro de Gobierno y Justicia } \\
\text { (MGJ) }\end{array}$ & Severino Mejía & PRD & Ex militar, abogado \\
\hline $\begin{array}{l}\text { Viceministro de Seguridad Pública } \\
\text { (MGJ) }\end{array}$ & Danilo Toro & PRD & Sociólogo \\
\hline Ministro de Gobierno y Justicia & Dilio Arcia & PRD & Abogado \\
\hline Ministro de Desarrollo Agropecuario & Olmedo Espino & PRD & Ingeniero \\
\hline Ministro de la Presidencia & Rafael Mezquita & PRD & Ingeniero \\
\hline Ministra de Comercio e Industrias & Gisela Álvarez de Porras & Ninguno & Abogada \\
\hline Viceministro de Finanzas (MEF) & José Simpson & PRD & Economista \\
\hline
\end{tabular}

El consejo de gabinete vigente en 2008 estuvo compuesto sólo por tres mujeres en cabeza de los Ministerios de Comercio e Industria, Desarrollo Social y Salud, frente a diez ministros varones, y por cinco viceministras frente a nueve viceministros. La mayoría de ellos son o han sido miembros del partido gobernante PRD. Algunos son reconocidos profesionales en sus campos de acción; unos pocos cargos de jerarquía media han sido designados a los partidos de la Alianza de gobierno. 
En otros importantes cargos del Ejecutivo, se nombró durante el 2008 a:

\begin{tabular}{|c|c|c|c|}
\hline Cargo & Nombre & Partido & Profesión/Ocupación \\
\hline $\begin{array}{l}\text { Directora del Instituto para la } \\
\text { Formación y Aprovechamiento de los } \\
\text { Recursos Humanos (IFARHU) }\end{array}$ & Yuealy Singh & PRD & Abogada \\
\hline Superintendente de Bancos & Olegario Barrelier & Ninguno & Banquero \\
\hline Secretario Presidencial de Metas & Luis Blanco & PRD & Abogado \\
\hline $\begin{array}{l}\text { Director del Sistema Nacional de } \\
\text { Protección Civil (SINAPROC) }\end{array}$ & Francisco Sucre & PRD & Médico \\
\hline $\begin{array}{l}\text { Gobernador }{ }^{1} \text { de la Provincia de Los } \\
\text { Santos }\end{array}$ & Mario Medina & PRD & \\
\hline $\begin{array}{l}\text { Gobernador de la Provincia de } \\
\text { Herrera }\end{array}$ & Luis Moreno & PRD & \\
\hline
\end{tabular}

En otras ramas del poder público se dieron los siguientes nombramientos:

\begin{tabular}{|c|c|c|c|}
\hline Cargo & Nombre & Partido & Profesión/Ocupación \\
\hline $\begin{array}{l}\text { Presidente de la Asamblea } \\
\text { Legislativa }\end{array}$ & Raúl Rodríguez & PRD & Abogado \\
\hline $\begin{array}{l}\text { Magistrado Corte Suprema de } \\
\text { Justicia }\end{array}$ & Oydén Ortega & Ninguno & Abogado \\
\hline $\begin{array}{l}\text { Magistrado Corte Suprema de } \\
\text { Justicia }\end{array}$ & Jerónimo Mejía & Ninguno & Abogado \\
\hline Fiscal General Electoral & Boris Barrios & Ninguno & Abogado \\
\hline Director (E) de la Policía Nacional & Jaime Ruiz & Ninguno & Policía \\
\hline Magistrado del Tribunal de cuentas & Álvaro Visuetti & Ninguno & Abogado \\
\hline Fiscal del Tribunal de Cuentas & $\begin{array}{l}\text { Carlos Quintanar } \\
\text { Rodríguez }\end{array}$ & Ninguno & Abogado \\
\hline Director de la Policía Nacional & $\begin{array}{l}\text { Comisionado Francisco } \\
\text { Troya }\end{array}$ & Ninguno & $\begin{array}{l}\text { Policía y Magíster en } \\
\text { Alta Gerencia }\end{array}$ \\
\hline
\end{tabular}

Adicionalmente, la Corte Suprema de Justicia eligió en 2007 como su Presidente a Harley James Mitchell y como Vicepresidenta a Esmeralda de Troitiño, para cumplir el mandato correspondiente a los años 2008 y 2009.

18 Dado el régimen de relaciones intergubernamentales de Panamá, las provincias son entidades meramente administrativas; por lo tanto, los Gobernadores son agentes desconcentrados del gobierno nacional y representantes del Presidente y del Ministro de Gobierno y Justicia, en los territorios, lo que implica que son funcionarios públicos de confianza y de libre nombramiento y remoción. 


\section{b. Funcionamiento del Gabinete}

El Consejo de Gabinete tiene funciones señaladas en la propia Constitución Política. Los Ministros de Estado dependen de la confianza del Presidente de la República que los nombra y los destituye. En ese sentido, las funciones del Consejo de Gabinete son ejercidas sin contradicción con las orientaciones dadas por el Presidente.

Un rasgo notable del funcionamiento del Consejo de Gabinete en la República de Panamá es la realización de reuniones del Consejo fuera de la ciudad de Panamá, que es la sede del gobierno, con la intención de poner al equipo de trabajo del Presidente de la República en contacto con los entornos en los que se ejecutan los programas gubernamentales.

\section{i. Estilo presidencial}

Martín Torrijos Espino, hijo del desaparecido ex dictador Omar Torrijos, ha mantenido durante 2008 el estilo de gobierno que ha caracterizado su gestión. La periodista local, Lina Vega Abad, en su contribución para el libro "Los telepresidentes" caracterizaba al mandatario panameño como un hombre de lenguaje sencillo y contacto directo, que utiliza el silencio para evadir situaciones complejas, que dilata al máximo la toma de decisiones, y que pone distancia entre él y los problemas delegando en su equipo el manejo de las crisis. ${ }^{19}$ Sin embargo, en la recta final de su mandato Torrijos ha tenido que enfrentar más tragedias, crisis y señalamientos que en los años anteriores, lo que se ha traducido en más silencios y más ausencias.

En 2008 el Presidente Torrijos tuvo que hacer frente a varios casos de corrupción que tocaron a su grupo de colaboradores más cercanos. También debió pasar por unas elecciones primarias en las que su liderazgo dentro del partido fue puesto a prueba y tuvo que sortear las múltiples manifestaciones por el alto costo de la vida producto de la inflación. Además, fue necesario atender el aumento de la violencia, la victimización y la percepción de inseguridad, los problemas de infraestructura y calidad en la educación pública, y la falta de calidad del transporte público. Asimismo, debió superar la tragedia del SAN-100 y las consecuencias de las inundaciones en Bocas del Toro y Chiriquí.

Todos estos problemas se encontraron con un Gabinete de alta rotación. Se presentó una disminución de 3 puntos en la aprobación del gobierno entre 2007 y 2008 en el Latinobarómetro; y la volatilidad de la calificación del Presidente medida por Dichter \& Neira que en 2008 nunca superó el 51\% en términos positivos (ver Gráfico 11).

\section{El Poder Legislativo}

El Legislativo panameño está constituido por una única cámara y se denomina Asamblea Nacional. El mandato parlamentario actual, 2004-2009, corresponde a 78 diputados. Durante 2008 siguió pendiente una demanda de inconstitucionalidad en la Corte Suprema de Justicia, que de resolverse podría adjudicar una nueva curul, por la modalidad de 
Gráfico 11: Calificación del Presidente Martín Torrijos

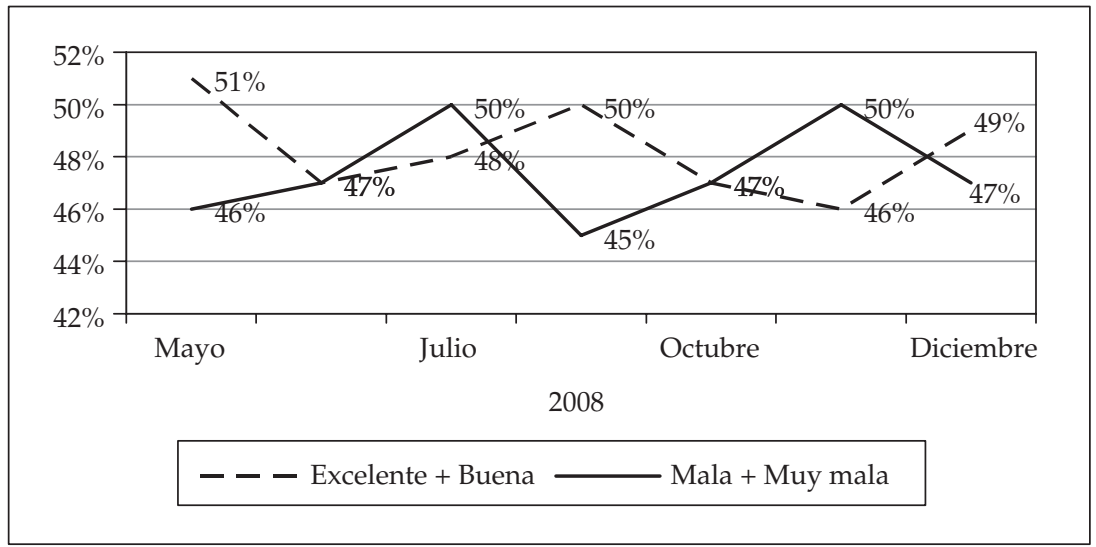

Fuente: Encuenta Dichter \& Neira, 2008.

Diputado por agregación que debió asignarse en 2004, elevando el número total de Diputados a 79.

La Asamblea se reúne en sesiones que se inician el primero de septiembre de cada año, y que se organizan en dos períodos de cuatro meses cada uno, denominados legislaturas. Sólo en 2009, el mandato parlamentario iniciará el $1^{\circ}$ de julio (efecto de las reformas constitucionales de 2004).

Los dignatarios de la Asamblea Nacional también se eligen anualmente, y son un Presidente y dos Vicepresidentes.

Los seis partidos representados en la Asamblea a finales de 2006 son:

Partido Revolucionario Democrático

Partido Popular

\section{Unión Patriótica}

Movimiento Liberal Republicano Nacionalista

Partido Panameñista

\section{Cambio Democrático}

Sólo el Partido Liberal y el Partido Vanguardia Moral de la Patria, adquirieron su personería durante el actual período constitucional y no tienen diputados electos bajo su postulación. Sin embargo, el Partido Vanguardia Moral de la Patria tiene una Diputada que lo integra (ex Partido Solidaridad). De hecho, la fusión entre el Partido Liberal Nacional y el Partido Solidaridad produjo otros movimientos de los Diputados que integraban su bancada, principalmente hacia el Partido Revolucionario Democrático.

Existen actualmente 21 comisiones permanentes en la Asamblea Nacional. De las comisiones permanentes, 20 están integradas por siete diputados, mientras que la Comisión de Presupuesto está integrada por quince diputados. 
Las comisiones permanentes debaten y aprueban el primer debate de todo Proyecto de Ley sometido a la consideración de la Asamblea Nacional.

Durante el segundo y tercer debates (plenarios) de los diferentes proyectos de ley, se utiliza el quórum deliberativo (un cuarto del total de diputados), y el quórum de votación (mayoría relativa para leyes ordinarias, y mayoría absoluta para leyes orgánicas).

El distinto objeto de las leyes es señalado en la Constitución Política. La mayoría de ellas son las denominadas orgánicas. Las leyes denominadas ordinarias en la Constitución panameñas son, paradójicamente, muy pocas. Únicamente son ordinarias las leyes que sirven al objeto de declarar la guerra, la que autoriza negociar la paz, la que declara amnistía para delitos políticos y la ley mediante la cual se aprueba el reglamento del régimen interno de la Asamblea Nacional. En 2008 se aprobaron 72 leyes, de las que 18 fueron convenios internacionales.

Entre las leyes expedidas durante 2008, resaltan la Ley 1 de 2008, aprobada por la Asamblea a fines de 2007, pero que fue sancionada y aplicada por el Ejecutivo a partir de enero de 2008. Esencialmente, es una ley que concede facultades extraordinarias al Ejecutivo, basada en el artículo 159, numeral 16 de la Constitución, para regular un conjunto de materias, entre las que destacó la modificación de aspectos importantes de la institucionalidad dedicada a la seguridad pública. El debate parlamentario sobre el Proyecto de Ley que llegó a ser finalmente aprobado, presentó la novedad de que se obligaba al Ejecutivo, antes de la expedición de los Decretos Ley correspondientes, de realizar un período de consultas con los sectores sociales interesados (algo absolutamente inédito en las leyes de facultades extraordinarias panameñas).

Las iniciativas legislativas del Ejecutivo fueron así receptoras, durante el mes de enero de 2008, de las observaciones de múltiples sectores críticos (incluidos del entorno gubernamental), y pese a que los Decretos finalmente aprobados fueron sustancialmente mejorados, no quedaron inmunizados frente a sus opositores, en especial los relacionados con la seguridad pública (demandas de inconstitucionalidad contra los cuales fueron presentados, y no resueltas todavía, al finalizar 2008).

La Ley 13 de 2008, que adopta medidas para el control del tabaco y sus efectos nocivos en la salud, es también una Ley destacable, por haber sido propuesta y aprobada conjuntamente por las bancadas de oposición y de gobierno, y por su inmediato efecto en la sociedad, restringiendo notablemente los lugares de consumo público de tabaco.

Por otro lado, y como resultados de la Concertación Nacional para el Desarrollo, se aprueban la Ley 20 de 2008, que aprueba el mecanismos de verificación y seguimiento de los acuerdos de la Concertación, y la Ley 34 de 2008, de responsabilidad social fiscal, donde se establecen las pautas para la administración financiera del Estado, y se asignan recursos para la ejecución de los acuerdos de la Concertación Nacional para el Desarrollo.

Como parte de la modificación legislativa necesaria para adaptar las políticas sociales, se aprobaron la Ley 29 de 2008, "que reforma artículos del Código Fiscal y de la ley 3 de 1985, como medida de apoyo al consumidor" y la Ley 30 de 2008, sobre beneficios a jubilados. 
La Ley 59 de 2008, que promueve el acceso universal a las tecnologías de la información de la comunicación, también fue aprobada.

Mediante la Ley 63 de 2008 se adoptó el nuevo Código de Procedimiento Penal, otro de los frutos legislativos del Pacto de Estado por la Justicia, y pieza indispensable para dar el giro propuesto en la jurisdicción penal nacional. Dispuso de una vacatio legis hasta el 2 de septiembre de 2009, y su principal característica es la adopción del modelo acusatorio.

La Ley 69 de 2008, por su parte, dictó el Presupuesto General del Estado para la vigencia del año fiscal 2009.

Como base para solucionar el problema de las denominadas "tierras colectivas", o tierras ocupadas por población indígena fuera de los territorios comarcales, se aprobó también la Ley 72 de 2008, que establece el procedimiento especial para su adjudicación.

\section{Relación entre los poderes del Estado}

\section{i. Relaciones Intergubernamentales}

No en pocas ocasiones se sostiene que Panamá es uno de los países más centralizados de América Latina, región en la que desde la tercera ola de democratización la descentralización ha sido una fórmula para acercar el Estado a los ciudadanos y mejorar la prestación de servicios públicos básicos mediante la canalización más eficiente de la inversión pública. Sin embargo, para Panamá esa afirmación no es del todo cierta. En 2004 la Constitución Política panameña fue reformada para introducir, entre otros elementos, la descentralización de la administración pública. Además, desde 1972 los municipios cuentan con un marco legal que les otorga competencias para impulsar el desarrollo económico local y una base gravable y fiscal para obtener recursos; sin embargo, 52 de los 75 municipios panameños no logran recaudar suficientes ingresos para cubrir las plantas mínimas de personal y mucho menos para realizar programas de desarrollo.

Tras años de concertación de una propuesta de ley que otorgue mayores competencias y recursos a los municipios y que introduzca elementos de nueva gerencia pública en las administraciones locales, y como corolario de las promesas de campaña del Presidente Torrijos, el 30 de diciembre de 2008 el Ejecutivo presentó a la Asamblea Nacional el proyecto de Ley de Descentralización.

El proceso de elaboración de la propuesta de ley, en el que intervinieron las asociaciones de alcaldes, representantes de corregimientos y municipios, fortaleció a estos actores y su capacidad de defensa de los intereses locales en un régimen político que tiende al personalismo y a la negociación como instrumentos de distribución de recursos.

\section{ii. Consejo de Gabinete}

El Consejo de Gabinete está integrado mayoritariamente por miembros del PRD. En la Asamblea la mayoría pertenece a la alianza de gobierno, integrada por los partidos PRD y PP. ${ }^{20}$ 
Las relaciones entre Ejecutivo y Legislativo han sido ágiles, facilitadas por la común orientación política y por la reelección del Presidente de la Asamblea Nacional en los períodos 2005-2006 y 2006-2007. Sin embargo, la elección en septiembre de 2007 del diputado Pedro Miguel González generó tensiones evidentes desde el mismo instante en que se anunció su postulación, por la animadversión estadounidense, que se expresó vigorosamente, amenazando incluso con dar al traste con el Tratado de Promoción Comercial entre Panamá y Estados Unidos, de enorme interés para el Ejecutivo. El elocuente discurso de toma de posesión de González el $1^{\circ}$ de septiembre de 2007 y la expectativa de sus críticos de que declinara en las semanas siguientes, finalmente frustradas, dieron paso a la resignación de sus oponentes y a la consolidación, a lo largo de 2008, de la relación de colaboración usual entre el Legislativo y el Ejecutivo.

Durante 2008 el Ejecutivo logró la aprobación de toda la legislación que consideró relevante presentar ante el Legislativo, y todas las ratificaciones de altas autoridades que necesitó. Algunos aspectos potencialmente problemáticos, como la legislación vía Decretos Leyes, o la objeción del Ejecutivo a varios proyectos aprobados por la Asamblea Nacional, no enturbiaron el clima de colaboración. La designación como Presidente de la Asamblea Nacional, 2008-2009, del diputado Raúl Rodríguez Araúz, contribuyó a restaurar completamente la situación anterior a septiembre de 2007.

La Corte Suprema de Justicia está compuesta por 9 magistrados y son designados por el Ejecutivo y sometidos a la aprobación de la Asamblea Nacional. Las últimas designaciones realizadas en diciembre de 2007, para iniciar en enero de 2008. ${ }^{21}$

\section{Relación entre los distintos niveles de gobierno}

El Estado panameño es unitario. De acuerdo con su división política Panamá está dividido en 9 provincias y 5 comarcas indígenas. Las provincias están divididas a su vez en distritos (de los cuales hay 75) y éstos en Corregimientos (de los que hay 621).

En las provincias, la autoridad máxima es el Gobernador de libre nombramiento y remoción por el Órgano Ejecutivo.

En el nivel distrital (municipal) el jefe de la administración es el Alcalde y en el Corregimiento es el Representante de Corregimiento. Los Representantes de Corregimiento de cada Distrito integran los diferentes Consejos Municipales, que son el "legislativo" municipal.

Tanto los alcaldes como los Representantes de Corregimiento son elegidos por votación popular directa por un periodo de 5 años, el mismo día de las Elecciones Generales.

En las comarcas indígenas están establecidos diversos regímenes administrativos, que en algunos casos reproducen el común al resto del Estado, pero que presentan algunas particularidades en atención a la organización tradicional de los distintos pueblos indígenas, y a razones de orden histórico.

21 Las designaciones correspondieron a Jerónimo Mejía (Sala Penal), en reemplazo de Graciela Dixon, y Oydén Ortega Durán (Sala Civil), en reemplazo de José Troyano. 


\section{Evaluación general sobre el funcionamiento y calidad de democracia}

Las características esenciales de la democracia representativa de partidos se han mantenido ininterrumpidamente desde principios de los noventa, pero se han producido cambios importantes en los dos procesos de reforma constitucional exitosos: 1994 y 2004.

La reforma constitucional de 2004 ha implicado la adaptación del ordenamiento legal, lo que ha sido particularmente importante en el ámbito electoral e institucional. Destaca sin duda la reforma del régimen jurídico de los Diputados y de la Asamblea Nacional, y la reforma del Código Electoral. A ese respecto, sin bien a finales de 2008 seguía pendiente la esperada reforma del Reglamento parlamentario, ya en 2006 se había adoptado el nuevo régimen del fuero procesal, según disponía la Constitución reformada.

En lo que respecta al régimen electoral, las elecciones de 2009 implicarán, por primera vez, la participación de candidatos de libre postulación al cargo de diputado. Esto da muestras de que la presión hacia la apertura del sistema político logra concesiones, lo que se hace aún más evidente a juzgar por episodios como el reclamo a favor de la libre postulación presidencial, que apareció articulada en 2008 alrededor de la figura del doctor Juan Jované.

Por otro lado, al tiempo que se ejercita la periódica competencia electoral entre partidos políticos desde 1990, se han utilizado con cada vez mayor frecuencia formas de concertación de los asuntos públicos. Esas formas de concertación, en particular los diálogos Estadopartidos políticos-sociedad civil propiciados por el sistema de Naciones Unidas, se han utilizado especialmente para la reforma de las instituciones públicas.

Así, se han establecido progresivamente órganos y procedimientos tendentes a llevar a la democracia panameña a un nivel que trascienda lo democrático-representativo. Algunos de estos procedimientos e instancias han sido incorporadas a la Constitución, o introducidas al ordenamiento jurídico mediante cambios legislativos. Se ha hecho también mucho énfasis en la creación y utilización de mecanismos de fiscalización de la actividad estatal, con el objeto de asegurar el acceso a la información pública y promover la transparencia y la rendición de cuentas.

El último proceso importante de concertación fue la "Concertación Nacional para el Desarrollo". Sin embargo, fuerzas significativas no participaron. Destacan los grupos de la izquierda más beligerante -agrupada en FRENADESSO- y el partido político en alza, Cambio Democrático (que postula a Ricardo Martinelli a la Presidencia de la República).

Pese a estas notables ausencias, durante 2008 empezó a legislarse respecto de los compromisos adquiridos durante la Concertación Nacional para el Desarrollo. Así, por ejemplo, en lo referente al establecimiento del Consejo de la Concertación Nacional y a las normas de Responsabilidad Fiscal. También se prepararon los proyectos de ley sobre descentralización y el proyecto de ley general de participación ciudadana.

La democracia panameña, en términos electorales, ha funcionado con regularidad desde principios de los años noventa. En cada elección los candidatos presidenciales oficiales han sido derrotados por márgenes no disputados, lo que ha asegurado la alternancia, y 
la sucesión PRD-Partido Arnulfista/Panameñista ha sido la regla. Si bien las elecciones de 2004 ya produjeron una modificación significativa, al quedar en segundo lugar el candidato de un tercer partido (en aquel caso, el candidato del Partido Solidaridad), son las próximas elecciones generales las que prometen un desvío profundo de la dinámica previa. La configuración del escenario electoral a fines de 2008 presenta la posibilidad de resultados inéditos, como la reelección del partido en el gobierno, o el ascenso de un candidato presidencial de oposición, no arnulfista/panameñista.

De modo semejante, existe la posibilidad de que la representación parlamentaria adquiera una dinámica diferente. Puede perderse la mayoría parlamentaria del PRD -constante con pocas excepciones desde 1994- y puede igualmente aparecer un escenario de auténtica dinámica multipartidista (al margen de que nominalmente ese ha sido el formato tradicional de la Asamblea Nacional) que haga más compleja la gobernabilidad.

Por otro lado, aunque el país creció económicamente por cuarto año consecutivo, teniendo perspectivas favorables incluso frente a la crisis financiera global de finales de 2008, es frecuente encontrar en los estudios de opinión pública que uno de sus resultados sea la falta de credibilidad de los panameños en los partidos políticos y, en general, en las instituciones democráticas. La aparición de señales de pérdida de vigor de las formas de pensamiento favorables a la democracia y a los valores de la tolerancia, que podrían desembocar en la quiebra de la representación democrática como ha estado organizada hasta ahora, es preocupante.

Los resultados del Barómetro de las Américas 2008, por ejemplo, identificaron un 71,6\% de opinión favorable a la democracia como la mejor forma de gobierno, que se reduce a $67,7 \%$ y a 51,9\% cuando se evalúa el respaldo a los valores claves de la participación y de la tolerancia política. Cuando se pregunta por la legitimidad del gobierno, la respuesta favorable disminuyó a 40,9\%, y sólo 26,7\% manifestó actitudes compatibles con el respaldo a una democracia estable. Los datos de 2008, en este respecto, significaron un notable retroceso, desde 37,8\% marcado en 2004.

La debilidad institucional se refleja de forma particular respecto de las políticas públicas. El Informe Nacional de Desarrollo Humano 2007-2008 (INDH), apoyándose en datos del BID, valora diversas dimensiones de las aplicadas en América Latina, reportando para Panamá niveles consistentemente bajos. De forma similar, la capacidad de la burocracia estatal queda en entredicho, al aparecer en último lugar en el Índice de Desarrollo del Servicio Civil.

Los principales retos para la democracia provienen por lo tanto de la debilidad institucional (advertida contundentemente en el INDH), combinada con uno de los peores esquemas de distribución de la riqueza y un malestar creciente con el sistema político en su conjunto.

Que el crecimiento de la economía haya servido de velo para disimular la fragilidad de la gobernabilidad democrática, puede reconocerse hoy sin discusión. Pero al concluir de forma drástica las condiciones internacionales favorables, la disminución de la actividad económica se sumará, en los años siguientes, a la delicada coyuntura. En ese contexto, la tendencia a expandir la participación ciudadana en la toma de decisiones, 
una de las características de la evolución reciente de la institucionalidad democrática panameña, puede colisionar con condiciones adversas, económicas y políticas. Destaca particularmente la plausible reducción de los recursos económicos, a consecuencia de la crisis global. Pero, si no mejora en forma significativa la capacidad de gestionar adecuadamente las políticas públicas enfocadas a atender los problemas sociales más importantes -educación, salud, empleo-, el resultado puede ser aún más complicado. Probablemente la nueva administración, que tomará posesión el $1^{\circ}$ de julio de 2009 , encontrará en esa situación el eje de su empeño por reparar las imperfecciones de lo que no era, en cualquier caso, paraíso alguno.

\section{REFERENCIAS}

Brown Araúz, Harry. 2007. "Elementos para un Marco Estratégico de Reformas Electorales en Panamá". Revista Panameña de Política (RPP), No. 3, Panamá, enero-junio, 9-44.

Fanovich, Sigeily y Sánchez, Salvador. 2007. "Panamá: El Canal como Palanca del Desarrollo". Revista Panameña de Política (RPP), No. 4, Panamá, julio-diciembre, 23-41.

García Diez, Fátima. 2003. "Panamá". En Partidos Políticos de América Latina. Centroamérica, México y República Dominicana, editado por Manuel Alcántara y Flavio Freindenberg. México: Fondo de Cultura Económica e Instituto Federal Electoral, 527-614.

García, Olmedo. 2005. "La pobreza en el marco de la globalización en Panamá". Cuadernos Nacionales (3ra. Época) 4. Panamá: Instituto de Estudios Nacionales, 39-47.

Guevara Mann, Carlos. 2007. “Observaciones en torno al sistema de elección y las campañas electorales de los diputados panameños". Revista Panameña de Política (RPP), No. 3, Panamá, enero-junio, 45-75.

"Calidad de la Representación Política y tamaño de las circunscripciones electorales: una comparación de las asambleas panameñas de 1945 y 1999". Revista Ciencia Política XXIV (2): 94-115.

Leis, Raúl Alberto. 2004. “Panamá: centralismo y metropolitización”. En Panamá: Cien Años de República, editado por Comisión Universitaria del Centenario de la República. Panamá: Editorial Universitaria.

Otero, Patricia. 2002. Partidos y Sistemas de Partidos en Panamá: Un estudio de la Estructuración Ideológica. X Encuentro de Latinoamericanistas Españoles, Salamanca.

Pizarro Sotomayor, Andrés. 2007. “Visitas In Loco de la CIDH e Informes Especiales sobre Panamá". Revista Panameña de Política (RPP), No. 3, Panamá, enero-junio, 108-152.

Sánchez González, Salvador. 2004. "La Transición a la Democracia en Panamá". En Historia General de Panamá (Volumen III, Tomo II), editado por Alfredo Castillero Calvo. Bogotá: Digital Designs Group, 283-301.

Sanmartín, Antonio. 2007. "Consideraciones en torno a la Fórmula de Asignación de Curules en los Circuitos Plurinominales". Revista Panameña de Política (RPP), No. 3, Panamá, enero-junio, 76-97.

Informe Nacional de Desarrollo Humano. 2007-2008. Programa de Naciones Unidas para el Desarrollo, noviembre 2008.

Cultura Política de la Democracia en Panamá. 2008. Latin American Publica Opinion Proyect (LAPOP). Orlando J. Pérez, Ph.D. y Mitchell A. Seligson, Ph.D. 
Clara Inés Luna es profesional en Gobierno y Relaciones Internacionales de la Universidad Externado de Colombia y Especialista en Comunicación Política y Pública del Instituto de Estudios Políticos de París-Sciences Po. Actualmente coordina el equipo de Descentralización y Reforma Institucional del Centro Regional para América Latina y el Caribe del Programa de las Naciones Unidas para el Desarrollo, en Panamá. Miembro del Centro de Iniciativas Democráticas de Panamá (CIDEM).

[E-mail clarai_luna@hotmail.com]

Salvador Sánchez es Panameño. Licenciado en Derecho y Ciencias Políticas por la Universidad Santa María La Antigua. Especialista en Derecho Constitucional y Ciencia Política, por el Centro de Estudios Constitucionales de Madrid, España. Profesor universitario desde 1993. Ha dictado los cursos de Derecho Constitucional, Ciencia Política y Derechos Humanos, entre otros. Actualmente es Director Nacional de Asesoría Legislativa, en la Asamblea Nacional de Panamá. Fundador en 1998 del CIDEM.

[E-mail salvasan@pty.com] 